Review Articles

\title{
Medical Abdominal Visceral Pain in Dogs
}

\author{
${ }^{1}$ Alice Catanzaro, ${ }^{1}$ Giorgia della Rocca, ${ }^{1}$ Alessandra Di Salvo and ${ }^{2}$ Mary Ellen Goldberg \\ ${ }^{1}$ Dipartimento di Medicina Veterinaria, Università Degli Studi di Perugia, Italy \\ ${ }^{2}$ Executive Secretary International Veterinary Academy of Pain Management, \\ Instructor VetMedTeam, LLC, Boynton Beach, FL, USA
}

Article history

Received: 23-12-2014

Revised: 26-12-2014

Accepted: 31-12-2014

Corresponding Author: Giorgia della Rocca

Dipartimento di Medicina

Veterinaria, Università Degli

Studi di Perugia, Italy

Email: giorgia.dellarocca@unipg.it

\begin{abstract}
Abdominal visceral pain of medical origin is one of the most frequent reasons for request of medical treatment in humans. Its control is of paramount importance not only for ethical reasons, but also because, if untreated, pain can cause a stress response leading to alterations concerning many organs and apparatuses. Causes of acute or chronic medical visceral pain in men are numerous, with pain originating from various regions of the body. Considering the similarities with regard to the nervous system between humans and other mammals, it is very likely that pathological conditions that cause visceral pain in men are painful in animals as well. Despite this, in veterinary practice medical visceral pain is rarely considered and poorly treated, often for the difficulty in its identification and for a lack of specific guidelines addressing this specific topic. Moreover, no detailed and specific information on this subject are available in the current literature. The present review lists the main pathologies likely responsible of medical abdominal visceral pain in the canine species, trying to summarize, for each considered condition, the available information regarding the pathogenesis and the management of pain.
\end{abstract}

Keywords: Abdominal Visceral Pain, Medical Painful Conditions, Dog, Pain Pathogenesis, Pain Treatment

\section{Introduction}

In human medicine, abdominal pain of medical origin is a frequent reason for request of medical care. Acute abdominal syndromes are very often accompanied by inflammation and pain. They are usually defined as "acute abdomen". However, abdominal pain can occur not only in acute conditions but also in chronic diseases (Jones and Ramakrishnan, 2005; Hansen, 2009).

In humans, medical abdominal pain can arise from different body areas, such as abdominal wall, diaphragm, spine, gastrointestinal tract, liver, pancreas, peritoneum, spleen, urinary tract and reproductive system. Gastric ulcerations, gastroenteritis, Irritable Bowel Syndrome (IBS), pancreatitis, cystitis, urolithiasis, endometriosis and prostatitis can be addressed as some of the most common causes of visceral pain (Wong and Mayer, 2006). Each of these diseases recognizes specific pain mechanisms, the understanding of which is critical for setting an adequate diagnostic and therapeutic plan.

Many pathophysiologic mechanisms involved in the onset of visceral pain are in common with somatic pain. However, specific features (e.g., dedicated pain pathways, specific neurotransmitters, peculiar mechanisms leading to hyperalgesia) characterize visceral pain (Catanzaro et al., 2014).

Several conditions responsible for medical abdominal pain in man can affect animals as well. Moreover, there are a lot of anatomical and functional similarities in the nervous system between man and other mammals and most of the studies aimed to understand human visceral pain mechanisms are performed on animal models. Thus, it is very likely that also animals can suffer medical abdominal pain in an acute or recurrent/chronic way, either as a primary problem or as a secondary complication to a primary disease (Fox, 2010).

In canine patients, current knowledge about visceral pain management concerns mostly postoperative analgesia after ovariohysterectomy (Leece et al., 2005; Boscan et al., 2011a; Camargo et al., 2011; Morgaz et al., 2013; Tsai et al., 2013), while little is known about non-surgical-induced visceral pain, with the exclusion of pancreatitis (Mansfield and Beths, 2015). Also, the recently published WSAVA Guidelines for recognition assessment and treatment of pain (Mathews et al., 2014) dedicate only a very short paragraph to medical pain. 
The lack of literature on this issue in veterinary medicine is probably related to the difficulties to identify the presence of visceral pain in animals. Although many efforts have been done in order to identify pain behaviours and expressions as well as physiologic pain indicators (Mathews et al., 2014; Wiese, 2015), they are not commonly taken into consideration by veterinarians within the diagnostic process in the daily clinical setting. Many pain scales, mono- or multi-parametric, have been drawn up for their use as a diagnostic aid in various canine acute and chronic painful conditions. However, they have been validated for pain of surgical origin (Firth and Haldane, 1999; Laboissière, 2006; Reid et al., 2007) or for osteoarthritic pain (Brown et al., 2007; 2008; Hielm-Björkman et al., 2009) and no tools for the evaluation of medical visceral pain are available at the moment.

Whatever the origin, the control of pain is of fundamental importance not only because of the physical and mental suffering that it determines, but also because, when not treated, pain induces a stress response that results in alterations of numerous organs and systems and in a slowing-down of healing processes (Melzack, 1999; Muir III, 2009).

This review summarizes the available information about the main pathologies likely responsible of medical abdominal visceral pain in the canine species, trying to point out the pathogenesis of pain in each condition. When supported by bibliographic indication, pain management is addressed as well.

\section{Painful Medical Abdominal Pathologies in the Dog}

In animals as in humans, most of the acute conditions of medical origin that affect the abdomen are highly painful. By a pathophysiologic point of view, pain is due to inflammation, ischemia or distension of a hollow viscous, sudden distension of an organ capsule and ligament traction (Orlandini, 2005; Giamberardino et al., 2005; ArendtNielsen and Drewes, 2009; Fonda, 2009). In addition to acute conditions, medical abdominal pain can also arise from chronic abdominal illness (Mathews, 2008).

Since every single abdominal organ could represent a source of pain, the list of painful pathologies is very long. In the following paragraphs, the most frequent medical abdominal painful conditions that may occur in the canine practice will be addressed.

\section{Gastrointestinal Tract}

Gastrointestinal (GI) tract is a frequent site of disease in veterinary patients. Several conditions originating from different causes can affect different portions of this apparatus. Most of them are likely accompanied by a certain degree of pain.

The exact mechanisms underlying GI pain in dogs have not been fully clarified. However, it is likely that pain accompanying GI pathologies is mainly caused by inflammation or ischemia.
Gastritis, gastric erosions/ulcers and gastric dilation/volvulus are the main painful diseases with regard to the gastric compartment, while acute enteritis, intestinal obstructions and Inflammatory Bowel Disease (IBD) represent the intestinal painful pathologies most commonly seen in the canine practice.

\section{Gastritis}

Acute gastritis is defined as a syndrome characterized by a sudden onset of vomiting related to an insult or to inflammation of the gastric mucosa (Simpson, 2007). It can be caused by the ingestion of trash, food intolerance/allergy, drugs (e.g., NSAIDs), infectious diseases, parasites, toxics, or it can be secondary to hepatic, renal, pancreatic or endocrine diseases.

Each of these conditions produces alteration in the gastric environment and inflammation. With inflammation, a large number of inflammatory mediators are released, such as prostaglandins, bradykinin, vanilloids, ATP, endocannabinoids, endogenous opioids, substance $\mathrm{P}$, glutamate, gamma-aminobutyric acid (GABA), catecholamines, serotonin (5HT), Cholecystokinin (CCK), Calcitonin Gene Related Peptide (CGRP) and histamine (Laird and Schaible, 2005; Fonda, 2009; Holzer and Holzer-Petsche, 2009). The latter is both involved in the inflammatory response and in further release of gastric juice, which is able to diffuse trough the tight junctions, thus contributing to further mucosal damaging and inflammation (Hedlund and Fossum, 2008). The inflammatory mediators directly stimulate visceral nociceptors located within the gastric wall, or sensitize them to further stimuli. Moreover, spasms of the muscular wall of the stomach and of the gastric sphincters (esophageal or phyloric) (Hedlund and Fossum, 2008) could contribute to the onset of pain.

In literature, abdominal pain from gastritis is only rarely reported and specific pain therapy is not mentioned. However, it is in the author opinion that being gastric juice implicated in inflammation mechanism, the use of antiacids could contribute to relieve pain. In addition, anticolinergic drugs could reduce muscle spasm, thus reducing the abdominal discomfort.

\section{Gastric Erosions/Ulcers}

Gastric erosions/ulcers are due to a disruption of the mucosal protective barrier secondary to direct insults, interferences with gastric protective prostaglandins $\left(\mathrm{PGE}_{2}\right)$, mucus or bicarbonates, blood flow reduction or to hypersecrection of gastric juice. These events can be caused by some toxicants (e.g., sodium hypochlorite, hydrocarbons), drug administration (NSAIDs or steroids) or by tumours releasing histamine (mast cell tumour) or gastric juice (gastrinomas). More rarely, the disruption of the mucosal protective barrier is a result of renal or hepatic failure, hypoadrenocorticism or hypotension (Webb and Twedt, 2003; Laine et al., 2008). 
Gastric ulcers cause vomiting and pain because of the inflammatory response due to inflamed and necrotic tissues within the ulcerated area.

Some authors (Mathews, 2000) suggest the use of opioids (e.g., buprenorphine) when abdominal pain is present. The addition of mucosal protectors (sucralfate, misoprostol, ecc.) or antacids can reduce the action of gastric juice against the gastric wall, thus reducing the painful sensation. Metoclopramide and maropitant are used as antiemetic (Simpson, 2007). For the latter drug, an analgesic action has been hypothesised due to its antagonism toward the NK1 receptors, implicated in the transmission of the painful stimuli (Boscan et al., 2011b).

\section{Gastric Dilation/Volvolus (GDV)}

Gastric dilation is an acute dilation of the stomach due to the production of a large amount of gas. This condition may be secondary to the ingestion of fermentable food and is usually related to a functional or mechanical obstruction of esophageal or phyloric sphyncters, so that the gas produced cannot be eliminated. The dilation may be followed by the torsion of the stomach around the mesenteric axis. In both cases, the blood flow of the gastric wall can be partially or totally compromised, causing ischemia and eventually necrosis (depending on the severity of the torsion and on its duration) (Willard, 2006a).

The chemical and mechanical stimulation of nociceptors that follow the release of inflammatory mediators and the rapid distension of the gastric wall and of the anterior portion of the abdominal wall is the cause of the severe pain that always accompanies GDV.

Even if animals with GDV show clear signs of pain, a specific pain management is rarely put in place prior to the surgical approach. Opioids (fentanyl in bolus followed by CRI) are suggested as preoperative analgesic drugs. Low doses of ketamine added to opioids can be useful to control somatic pain and lidocaine could have beneficial effects both in pain management and in the cardiac stabilization. NSAIDs should not be used due to their potential side effects at the GI level (Wooten et al., 2010).

\section{Acute Enteritis}

Acute enteritis (or gastroenteritis) is an inflammation of the gut that can be due to noninfectious causes (e.g., ingestion of fatty food, new food introduced too rapidly, parasites) or to infectious agents (bacteria or viruses). One of the most common infectious agents is Canine Parvovirus (CPV-2) that affects mainly puppies (Willard, 2006b).

Pain is quite never considered as a symptom associated to these conditions, especially in puppies with parvovirus infection, probably because of the high level of depression that masks any sign of discomfort. However, considering the pathogenesis of enteritis, it is possible to hypothesize the presence of pain, sometimes prolonged and intense. Indeed, during enteritis, the inflammatory mediators released during the inflammatory process and the spasms of the muscular portion of the intestinal wall may contribute to the onset of abdominal pain. Histological examination of intestinal cells collected from gut of dogs with parvovirosis reveals inflammation and necrosis of the epithelial cells. Spasms of the intestinal wall mechanically stimulate the intestinal nociceptors. Moreover, the increase of intestinal motility can provoke an intussusception of part of the gut, followed by a reduction of the blood flow (due to the compression of blood vessels) and by ischemia that contributes to the pain pathogenesis (Poole et al., 1987).

Non-infectious gastroenteritis is often self-limiting. Supportive therapy (i.e., fluid therapy and specific food) is usually the only strategy considered for this condition. Pain is usually not taken in to account within the treatment protocol. Eventually, some authors recommend the use of opioids for their inhibitory effect on the intestinal motility rather than for their analgesic action (Willard, 2006b).

Also for infectious enteritis a symptomatic therapy is proposed: The main purpose is to avoid dehydration and bacterial overgrowth. An aggressive fluid therapy and an antibiotic, antiemetic and antidiarrheal therapy is recommended, but no analgesic drugs are usually included in the protocol. However, between antiemetic drugs, maropitant can have some analgesic effect (Boscan et al., 2011b). Opioids are recommended only in case of intussusception, when a surgical approach is needed (Hedlund and Fossum, 2008).

\section{Intestinal Obstruction}

Intestinal obstruction can be caused by the ingestion of foreign bodies or, less frequently, by the presence of a tumor.

Intestinal obstruction can be simple and abdominal pain is considered as rare, or complicated (e.g., when followed by an intussusception), in which case pain is always present and of high intensity (Willard, 2006b).

When pain is present, it seems to be related to ischemia rather than inflammation. Moreover, the obstruction blocks the intestinal content flow and a distension of the proximal portions of the intestine occurs, causing the activation of nociceptors. Pain is also due to the gut hypermotility that periodically occurs in the attempt to eliminate the blockage. Literature does not mention pain treatment for intestinal obstruction. A perioperative pain management is suggested when a complicated obstruction needs a surgical treatment (Mathews, 2000; Mathews et al., 2014). 


\section{Inflammatory Bowel Disease (IBD)}

A chronic intestinal pathology that only recently has acquired interest in veterinary medicine is IBD. The etiopathogenesis of this pathology is still not completely understood. IBD seems to be related to the action of inflammatory and immune cells (Gut Associated Lymphoid Tissue, GALT) on the intestinal wall. Lymphocytes $\mathrm{B}$ and $\mathrm{T}$, prostanoids, leukotrienes, cytokines, nitric oxide and other mediators seem to be involved in this process. Moreover, hypersensitivity reactions (type I and IV) contribute to the increase of inflammatory cells concentration. The inflammatory process damages the intestinal mucosa and ends in alterations of intestinal motility and diarrhea (Jergens, 2009). A neuropathic component has also been taken in to account in the pathogenesis of IBD (Mathews, 2008).

In veterinary literature, the presence of pain is reported only if IBD is associated to erosions/ulcers of the mucosa. However, the presence of inflammation may cause pain also in non-complicated forms. Moreover, the alteration of gut motility and spasms of the muscular wall, which often follow gut inflammation, can directly or indirectly contribute to pain. Pain is probably supported by an interaction between inflammatory or immune cells and the intestinal nervous system: an altered stimulation of free nerve endings may lead to an abnormal conduction of pain sensations.

Not considering pain among the clinical signs of IBD, the use of analgesics is not considered. Food control, steroids and other drugs such as azathioprine, metronidazole or sulfasalazine are recommended for the treatment of this condition (Jergens, 2012).

\section{Pancreas}

\section{Pancreatitis}

The most common pathology that can affect the pancreas in the dog is acute or chronic pancreatitis. Acute pancreatitis can be mild (e.g., interstitial pancreatitis), or severe (e.g., when associated to necrosis, haemorrhage or abscesses). Chronic pancreatitis is due to the recurrence of acute pancreatitis episodes.

Pain associated to pancreatitis is widely reported in literature (Mathews, 2000; Mansfield and Beths, 2015). Actually, pancreatitis is recognised as one of the most painful pathologies affecting the abdominal compartment, leading to pain from mild to excruciating (Mansfield and Beths, 2015). Pain is easily identified during the clinical exam. Frequent signs of pain are a crouched appearance and guarding of the abdomen on palpation (Mansfield and Beths, 2015), a "prayer position" (Fig. 1) or the research of a cold surface. Clinically, abdominal pain can be localized to the anterior portions of the abdomen or be generalized (leading to acute abdomen) (Williams and Stainer, 2007).

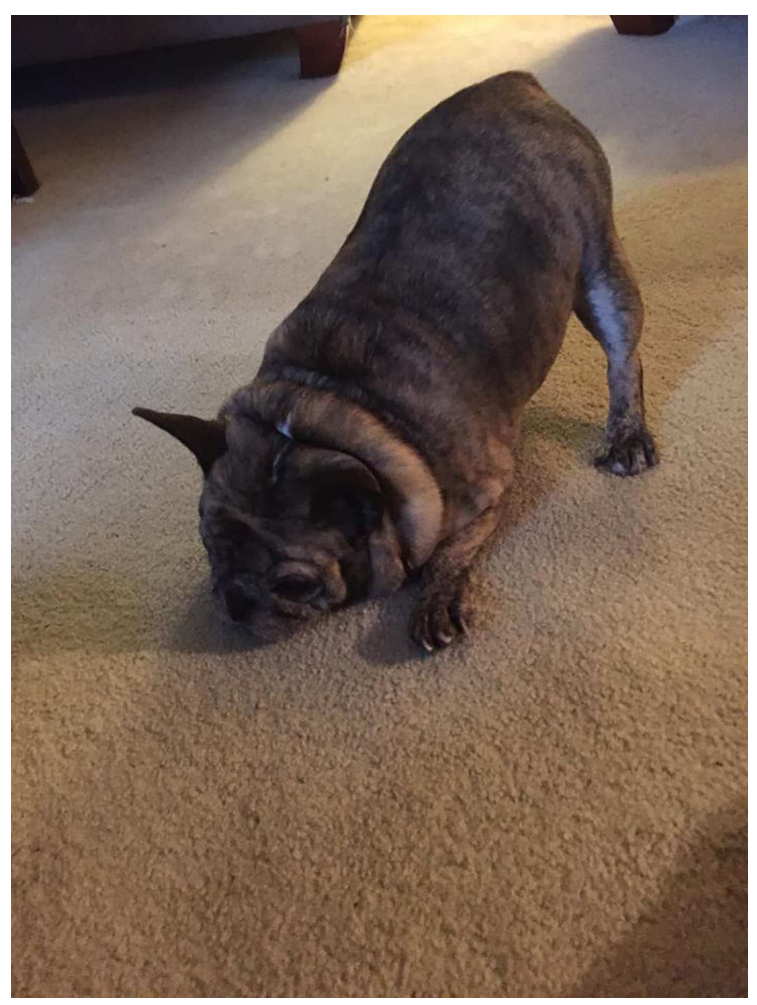

Fig. 1. Dog in "prayer position"

The mechanisms underlying pain during pancreatitis are related to the inflammation process and to the action of digestive enzymes delivered by the affected cells. In fact, during pancreatitis episodes, digestive enzymes are released in big amount and act against the organ itself causing necrosis of pancreatic cells, but also against stomach, small intestine and colon. In this case acute abdomen is observed.

Due to the known consequences of excruciating pain (cardiocirculatory shock), a pain therapy is always recommended in dogs where pancreatitis has been diagnosed (Williams and Stainer, 2007). Opioids such as methadone, meperidine, hydromorphone, buprenorphine or butorphanol, can be used to treat pancreatic pain (Whittemore and Campbell, 2005; Mathews, 2008; Mansfield and Beths, 2015). Intramuscular or subcutaneous morfine, while having good analgesic effect may cause obstruction of pancreatic duct. However if administered in the epidural space it seems not to have this secondary effects. In case of very intense pain, a CRI of fentanyl, ketamine or lidocaine should be considered (Whittemore and Campbell, 2005; Mansfield and Beths, 2015).

\section{Liver}

The pathologies affecting the dog's liver likely accompanied by abdominal pain are colelithiasis, hepatic lobe torsion and hepatic abscesses or cysts. 


\section{Colelithiasis}

Colelithiasis is often an accidental finding during necropsies. Colecystitis, colangiohepatitis or biliary obstruction are due to the accumulation of biliary stones within the hepato-biliary apparatus. Colelithiasis in accompanied by fever, jaundice, anorexia, vomiting and abdominal pain (Fossum, 2008a). As reported by Mathews (2000), levels of pain associated with necrotizing cholecystitis is from severe to excruciating.

Pain is likely due to the inflammatory process that follows the mechanical action of the stones on the gallbladder, hepatic and biliary duct walls and to the distension of hepatic and biliary ducts due to the biliary stasis.

This pathology needs a surgical correction, thus a conservative analgesic therapy is not indicated in literature. As for many surgical procedures, the administration of pure opioids is recommended (Mathews et al., 2014).

\section{Hepatic Lobe Torsion}

Hepatic lobe torsion is a very rare condition. The lobe most involved is the left lateral lobe. When lobe torsion occurs, pain is probably secondary to necrotic events, capsule distension and ligament traction. In fact, the torsion causes an obstacle to the blood flow so that hepatic cells cannot receive an adequate blood and oxygen supply and necrotic events take place. Secondary to the blood flow interruption, a congestion of the organ occurs, causing the capsule distension that contributes to the development of pain.

When a lobe torsion is diagnosed, a surgical correction is needed. Pure opioids are recommended (Mathews et al., 2014). Morphine should not be injected IV because the consequent histamine release could cause a spasm of the hepatic vein muscular wall and further congestion (Fossum, 2008b).

\section{Hepatic Abscessed or Cysts}

The occurrence of hepatic abscesses or cysts is the result of a septic embolization secondary to a bacterial infection affecting the abdominal cavity. E. Coli, Clostridium spp., Klebsiella pneumoniae, enterococcus spp, staphylococcus epidermidis and streptococcus intermedius are the most frequent etiological agents. These bacteria can originate from onphalophlebitis in puppies, or from pancreatitis or biliary inflammation in adults (Farrar et al., 1996; Bunch, 2006).

Literature reports the presence of intermittent pain (Bunch, 2006). Pathophysiology of pain related to this pathology in dogs has not been clarified yet, but it is probably related to the inflammatory response trying to eliminate the etiological agent, or to capsule distension due to pus accumulation.
Even though abdominal pain is commonly recognized in dogs affected by these pathologies, the recommended therapy accounts only for antibiotics (Bunch, 2006); no indication is available with reference to analgesic drugs.

\section{Spleen}

Two potentially painful condition associated with splenic diseases are the torsion of the spleen and the hemangiosarcoma.

\section{Splenic Torsion}

The splenic torsion generally accompanies the GDV, although congenital anomalies and traumatic ruptures of the gastro-splenic or spleno-colic ligament can be sometimes associated with this pathology. Splenic torsion can be an acute as well as a chronic event. The rotation of the spleen around its vascular pedicle causes a venous stasis within the organ, which can evolve in a relatively short time in a widespread organ necrosis. Even hepatic, renal and cardiovascular diseases and hyperadrenocorticism can trigger alterations of the splenic blood flow and induce a congestive state (Fossum, 2008d).

The torsion of the spleen is accompanied by abdominal pain, which is due to the organomegaly and the following distension and stretching of the splenic capsule. In case of development of cellular necrosis, the action of lisosomial enzymes, histamine and kinins relesed by damaged cells contributes to the onset of pain.

This pathology needs a surgical correction, thus a conservative analgesic therapy is not indicated in literature.

\section{Hemangiosarcoma (HSA)}

The HSA is the most frequent spleen tumor in the dog. The splenic HAS is an invasive neoplasia that frequently metastasizes to liver, mesentery and brain. It is characterized by vascular congestion, fibrosis and necrotic areas (Fossum, 2008d).

Pain is not mentioned among the symptoms accompanying HSA. However, due to the distension of the splenic capsule and the cell death, pain would probably be present. Information regarding pain management in dogs with HSA is not available so far.

\section{Urinary Tract}

The urinary tract can be the location of painful pathologies due to inflammation (e.g., cystitis, urolithiasis), ischemia (e.g., acute renal failure) or other not yet clarified causes (e.g., chronic renal failure).

\section{Cystitis and Urolithiasis}

Cystitis (i.e., the inflammation of the urinary bladder mucosa) can be caused by bacteria derived from the low urinary tract. One of the most common agents of cystitis in dogs is E. Coli. 
Even if the presence of abdominal pain in animals affected by cystitis is recognised, the recommended treatment accounts only for the use of antibiotics; analgesics are not considered (Green and Schott, 1988).

Cystitis can also occur secondly to urinary stones. Dog's breed (e.g., Dalmatian), unbalanced diet, reduction in renal absorption or augmented excretion of minerals, represent some predisposing factors to formation of urinary stones. Urinary stones can be located into the kidney (nephrolithiasis), ureters (ureterolithiasis), urinary bladder (cystolithiasis) or into the urethra (uretrolithiasis) (Grauer, 2006).

Abdominal pain usually located in the caudal portions of the abdomen is often associated to this condition, as stones, especially those with an irregular surface, have an irritating action on the mucosa, which leads to inflammation and pain. Moreover, pain is also consequent to the spasm of the musculature around the stones. In case of uretrolithiasis, over-distension of the urinary bladder due to the decreased urine outflow also occurs, thus contributing to discomfort and pain.

Even though animals with this condition are clearly painful, a specific pain therapy is not reported in literature. However, the use of miorelaxants is recommended in order to reduce muscular spasm and facilitate the elimination of the stones (Greene and Scott, 1988).

\section{Acute and Chronic Renal Failure}

In veterinary literature, the occurrence of abdominal pain associated to acute or chronic renal failure is not reported. Actually, the profound depression that usually accompanies this pathology hides any eventual signs of pain. However, the presence of pain is highly probable, as renal failure is characterized, among other alterations, by oedema of the kidney, followed by distension of the renal capsule and consequent activation of nociception. The nociceptive stimulation is probably increased if renal failure is concomitant to a pyelonephritis, that causes a larger distension of the capsule and an inflammatory condition (Orlandini, 2005).

Since pain is not considered as a symptom, an analgesic treatment is usually not provided.

\section{Reproductive Apparatus}

According to human literature, the most common painful pathologies related to the reproductive apparatus are pyometra and prostatitis. In veterinary literature, pyometra, usually called cystic endometrial hyperplasiapyometra complex, is not mentioned as a cause of pain and neither is prostatitis. However, being both pathologies characterized by inflammation, a certain degree of abdominal pain or discomfort is likely present.

\section{Pyometra}

Pyometra is a uterine infection caracterized by an accumulation of pus inside the uterus, often consequent to the action of progesterone. This hormone stimulates the secretion of uterine glands, maintains the cervix closed and blocks the contractile activity of the myometrium. Bitches are predisposed to this condition because their levels of progesterone remain high during all phases of the reproductive cycle. If this condition is not quickly treated, an endotoxiemia and a subsequent marked depression occur (Kustritz, 2007). The depression masks any signs of pain and thus an analgesic treatment for this condition is not taken in to account.

\section{Prostatitis}

Prostatitis is an inflammation of the canine prostate caused by a bacterial infection like E. Coli, Pseudomonas spp, Staphylococcus spp, Streptococcus spp or Proteus. These bacteria initially cause the formation of microabscesses that can converge in macroabscesses. Sometimes, these macroabscesses break, leading to peritonitis and sepsis (Johnson, 2006).

In men, prostatitis is accompanied by depression, fever, dehydration, vomiting, tenesmus, difficulty in urination, preputial discharge and abdominal pain. Pain may be very intense especially when prostatitis is worsened by the presence of abscesses (Johnson, 2006; Parry, 2007).

In dogs, the same condition leads to a deep depression that masks any sign of pain, which is thus not considered in the treatment protocol. In fact, despite intense pain is likely present, no direct pain management is usually prescribed and only antibiotics are recommended as a therapy for this condition.

\section{Peritoneum}

\section{Peritonitis}

Peritonitis is an inflammation of the peritoneum. It can be a primary condition or can be secondary to other organs' pathologies. Primary peritonitis is very rare and is due to the migration of bacteria to the peritoneum through the haematic or lymphatic circulation (Zimmermann et al., 2006). Secondary peritonitis can be septic or aseptic. Septic peritonitis is due to the rupture/perforation of gastrointestinal or urinary tract and the passage of bacteria (Eubacterium, Clostridium spp., Streptococcus spp., Escherichia Coli, Klebsiella, Pseudomonas, Bacteroides spp, Proteus spp, ecc.) in the abdominal cavity. This event can be related to traumas, cancers, ulcers, intussusceptions, obstructions, foreign bodies, GDV and other causes. Bacteria can also spread from the rupture of pancreatic or prostatic abscesses, uterus or gall bladder, torsion of hepatic lobes, as well as from iatrogenic causes. The aseptic form is related to the leak of chemical substances, like bile and urine, inside the peritoneum, or it can be a consequence of a flogosis of any abdominal organ (as during pancreatitis) (Specht et al., 2002; Willard, 2006c; Fossum, 2008c). 
Peritonitis can be acute or chronic. Acute peritonitis is always accompanied by pain from severe to excruciating (Willard, 2006c). It may be localized, but generalized pain is more common and the animal will often tense or "splint" the abdomen during palpation (Fossum, 2008c). Cutaneous hyperestesia can also be present (Weinstein et al., 2005). Pain is likely due to the action of lisosomial enzymes, histamine and kinins relesed by damaged cells. Indeed, cellular hypoxia and death follow hypotension and hypovolemia that occur during peritonitis. The activation of the inflammatory pathways leads to the activation of the arakidonic acid pathway, with production of free radicals and thromboxane A2 that contribute to the activation of peritoneal nociceptors (Dulisch, 2001).

Chronic peritonitis is not always a painful condition. When pain is present, it is probably related to the traction of vessels and visceral ligaments due to the fibrinogen lacinias or to the reactivation of the inflammatory process. In severe cases, the formation of a large amount of free fluid inside the abdomen (ascites) can cause distension of abdominal wall and pain (Willard, 2006c).

While an antimicrobial therapy is recommended once septic peritonitis is suspected or confirmed, no information are available in literature about the management of pain associated to peritonitis.

\section{Conclusion}

From those reported in the previous section, there is a clear lack of information about the analgesic treatment of pathological medical conditions associated with visceral abdominal pain in the dog. The only two conditions for which an analgesic treatment is clearly described in veterinary literature are gastric ulcers and pancreatitis, while for all other conditions, guidelines concerning a spceific analgesic treatment are not available. The therapeutic approach of illnesses related to the various abdominal organs is limited to a symptomatic therapy, often only intended to remove the cause of the disease.

Due to the consequences of pain on morbidity and mortality, when visiting a patient with an abdominal issue the veterinary practitioner should start to consider pain among symptoms that accompany the pathology and that deserve to be alleviated.

Many of the aforementioned conditions need to be surgically treated. Actually, also if a surgery has been scheduled, an analgesic therapy should be administered as soon as possible, not only in proximity of the surgery, in order to relieve pain and contribute to patient stabilization.

All abdominal painful conditions should be treated according to the severity of pain as well as to its pathogenesis. With regard to the last point, each of the aforementioned diseases recognizes specific pain mechanisms, the understanding of which is critical for setting a diagnostic reasoning and an adequate therapeutic treatment. Mathews (2000) and the WSAVA Guidelines for recognition assessment and treatment of pain (Mathews et al., 2014) propose different protocols on the basis of acuteness and severity of the disease. Even though these are not specifically indicated for abdominal pain management, they can help the practitioner to decide the correct approach.

For acute conditions, pure opioids (e.g., morphine, fentanyl) and ketamine, or butorphanol and buprenorphine are recommended, for a moderate/severe pain and for mild/moderate pain, respectively.

When pain is persistent, if not contraindicated, NSAIDs can be associated to the aforementioned drugs, whether the pain is mild, moderate or severe.

If a neuropathic component is involved in the pathogenesis of pain, drugs that target neuropathic pain should be included in the therapeutic protocol. Particularly, drugs used in the human setting to treat pain of neuropathic origin, such as inhibitors of N-type Ca channels (gabapentin, pregabalin) and serotonin and noradrenaline reuptake inhibitors (TCAs, SSRIs, SNRIs) seem to be efficacious in animals as well.

The severity of pain should influence not only the choice of the class of drug, but also the dosage of some drugs such as opioids and gabapentinoids (the more severe the pain, the more high the doses) (Mathews, 2000; Mathews et al., 2014).

It is particularly desirable that further studies aimed to identify clear clinical and behavioural markers for the assessment of medical visceral pain in the dog will be carried out and that appropriate guidelines specifically drafted for manage such type of pain will be soon available. Indeed, with new information gathered on this topic, veterinary practitioners will be offered an additional tool to better look after their patients' welfare.

\section{Author's Contributions}

Alice Catanzaro: Conceived the review and wrote the manuscript.

Giorgia della Rocca: Contributed to write the text.

Alessandra Di Salvo: Searched for references.

Mary Ellen Goldberg: Contributed to the contents and checked for English spelling.

\section{Ethics}

No ethical issues are concerned with the present article.

\section{References}

Arendt-Nielsen, L. and A.M. Drewes, 2009. Experimental Visceral Pain. In: Visceral Pain, Giamberardino, M.A. (Ed.), Oxford University Press, New York, USA, ISBN-10: 0199235198, pp: 21-30. 
Boscan, P., E. Monnet, K. Mama, D.C. Twedt and J. Congdon et al., 2011a. A dog model to study ovary, ovarian ligament and visceral pain. Vet. Anaesthesia Analgesia, 38: 260-266.

DOI: $10.1111 / \mathrm{j} .1467-2995.2011 .00611 . x$

Boscan, P., E. Monnet, K. Mama, D.C. Twedt and E.P. Steffey, 2011b. Effect of maropitant, a neurokinin 1 receptor antagonist, on anesthetic requirements during noxious visceral stimulation of the ovary in dogs. Am. J. Vet. Res., 72: 1576-1579. DOI: 10.2460/ajvr.72.12.1576

Brown, D.C., R.C. Boston, J.C. Coyne and J.T. Farrar, 2007. Development and psychometric testing of an instrument designed to measure chronic pain in dogs with osteoarthritis. Am. J. Vet. Res., 68: 631-637. DOI: 10.2460/ajvr.68.6.631

Brown, D.C., R.C. Boston, J.C. Coyne and J.T. Farrar, 2008. Ability of the canine brief pain inventory to detect response to treatment in dogs with osteoarthritis. J. Am. Vet. Med. Assoc., 233: 1278-1283. DOI: $10.2460 /$ javma.233.8.1278

Bunch, S.E., 2006. Patologie Epatobiliari Nel Cane. In: Medicina Interna Del Cane e Del Gatto, Nelson, R.W. and C.G. Couto (Eds.), Elsevier, Torino, Italy, ISBN-10: 8821432793, pp: 540-560.

Camargo, J.B., P.V. Steagall, B.W. Minto, S.E. Lorena and E.S. Mori et al., 2011. Post-operative analgesic effects of butorphanol or firocoxib administered to dogs undergoing elective ovariohysterectomy. Vet. Anaesthesia Analgesia, 38: 252-259. DOI: 10.1111/j.1467-2995.2011.00609.x

Catanzaro, A., A. Di Salvo, A. Polisca and G. Della Rocca, 2014. An overview of the pathophysiology of visceral pain. J. Vet. Sci. Med. Diagn., 3: 2. DOI: $10.4172 / 2325-9590.1000135$

Dulisch, M., 2001. Peritoniti. In: Le Basi Patogenetiche Delle Malattie Chirurgiche Nei Piccoli Animali. M.J. Bojrab and A. Spadari, (Eds.), Giraldi, Rimini, Italy, pp: 147-151.

Farrar, E.T., R.J. Washabau and H.M. Saunders, 1996. Hepatic abscesses in dogs: 14 cases (1982-1994). J. Am. Vet. Med. Assoc., 208: 243-247. PMID: 8567382

Firth, A.M. and S.L. Haldane, 1999. Development of a scale to evaluate postoperative pain in dogs. J. Am. Vet. Med. Assoc., 214: 651-9.

Fonda, D., 2009. Dolore Viscerale. In: Dolore e Analgesia Negli Animali, Fonda, D. (Ed.), Point Veterinaire Italie, Milano, Italy, ISBN-10: 8895995619, pp: 295-309.

Fossum, T.W., 2008a. Chirurgia Delle Vie Biliari Extraepatiche. In: Chirurgia Dei Piccoli Animali, Fossum, T.W. C.S. Hedlund and A.L. Johnson (Eds.), Elsevier Masson, Milano, Italy, ISBN-10: 8821430324, pp: 569-582.
Fossum, T.W., 2008b. Chirurgia Del Fegato. In: Chirurgia Dei Piccoli Animali, Fossum, T.W., C.S. Hedlund, A.L. Johnson (Eds.), Elsevier Masson, Milano, Italy, ISBN-10: 8821430324, pp: 540-568.

Fossum, T.W., 2008c. Chirurgia Della Cavità Addominale. In: Chirurgia Dei Piccoli Animali, Fossum, T.W., C.S. Hedlund and A.L. Johnson (Eds.), Elsevier Masson, Milano, Italy, ISBN-10: 8821430324, pp: 324-345.

Fossum, T.W., 2008d. Chirurgia del Sistema Emolinfatico. In: Chirurgia dei Piccoli Animali, Fossum T.W. (Ed.), Elsevier Masson, Milano, Italy, ISBN-10: 978-88-214-3032-9, pp: 611-645.

Fox, S.M., 2010. Physiology of Pain. In: Chronic Pain in Small Animal Medicine, Fox, S.M. (Ed.), Manson Publishing, London, UK, ISBN-10: 1840765674 , pp: 11-73.

Giamberardino, M.A., G. Affaitati and R. Costantini, 2005. Il Dolore Viscerale. In: Il Dolore. Valutazione, Diagnosi e Trattamento, Mercadante, S. (Ed.), Masson, Milano, Italy, ISBN-10: 8821427838, pp: 172-180.

Grauer, F.G., 2006. Urolitiasi Nel Cane. In: Medicina Interna Del Cane E Del Gatto. Nelson, R.W. and C.G. Couto (Eds.), Masson, Milano, Italy, ISBN-10: 8821432793, pp: 651-662.

Greene, R.W. and R.C. Scott, 1988. Malattie Della Vescica e Dell'uretra. In: Trattato Di Medicina Interna Veterinaria: Malattie Del Cane E Del Gatto, Ettinger, S.J. and E. Vitali (Eds.), Edizioni SBM, Noceto (Parma), Italy, pp: 1890-1936.

Hansen, B., 2009. Critical Care Analgesia: Abdominal Pain. UBM Advanstar.

Hedlund, C.S. and T.W. Fossum, 2008. Chirurgia Dell'apparato Digerente. In: Chirurgia Dei Piccoli Animali, T.W. Fossum, (Ed.), Elsevier Masson, Milano, Italy, ISBN-10: 8821424510, pp: 346-539.

Hielm-Björkman, A.K., H. Rita and R.M. Tulamo, 2009. Psychometric testing of the Helsinki chronic pain index by completion of a questionnaire in Finnish by owners of dogs with chronic signs of pain caused by osteoarthritis. Am. J. Vet. Res., 70: 727-734. DOI: 10.2460 /ajvr.70.6.727

Holzer, P. and U. Holzer-Petsche, 2009. Emerging Pharmacological Terapies. In: Visceral Pain, Giamberardino, M.A. (Ed.), Oxford University Press, New York, USA, ISBN-13: 978-0-19-923519-3, pp: 51-61.

Jergens, A.E., 1999. Inflammatory bowel disease: Current perspectives. Vet. Clinics North America: Small Animal Practice, 29: 501-521. DOI: 10.1016/S0195-5616(99)50032-6

Jergens, A.E., 2012. Feline idiopathic inflammatory bowel disease: What we know and what remains to be unraveled. J. Feline Medicine Surgery, 14: 445-458. DOI: $10.1177 / 1098612 X 12451548$ 
Johnson, C.A., 2006. Patologie Prostatiche. In: Medicina Interna Del Cane E Del Gatto. Nelson, R.W. and C.G. Couto (Eds.) Masson-Edizioni Veterinarie, Milano, Italy, ISBN-10: 88-85675-55-7, pp: 948-954.

Jones, A.D. and K. Ramakrishnan, 2005. Analgesics in the initial management of acute abdominal pain. Internet J. Emergency Med. DOI: 10.5580/22ac

Kustritz, M.V.R., 2007. Iperplasia Endometriale Cistica e Piometra. In: Clinica Medica Veterinaria. Malattie Del Cane e Del Gatto. Ettinger, S.J. and E.C. Feldman (Eds.), Elsevier Masson, Milano, Italy, ISBN-10: 8821429954, pp: 1715-1719.

Laboissière, B.L.A., 2006. Validation statistique des grilles 4A-Vet d'évaluation de la douleur postopératoire chez le chien et le chat. Thesis pour le diplôme d'Etat de Docteur Vétérinaire-Ecole Nationale Vétérinaire de Nantes, Nantes, France.

Laine, L., K. Takeuchi and A. Tarnawski, 2008. Gastric mucosal defense and cytoprotection: Bench to bedside. Gastroenterology, 135: 41-60. DOI: $10.1053 /$ j.gastro.2008.05.030

Laird, J.M.A. and H.G. Schaible, 2005. Visceral and deep somatic pain. In: The neurobiology of pain, Hunt, S. and M. Koltzenburg (Eds.), Oxford University Press, New York, USA, pp: 239-266. ISBN-10: 0-19-851561-8.

Leece, E.A., J.C. Brearley and E.F. Harding, 2005. Comparison of carprofen and meloxicam for 72 hours following ovariohysterectomy in dogs. Vet. Anaesthesia Analgesia, 32: 184-192. DOI: $10.1111 / \mathrm{j} .1467-2995.2005 .00207 . \mathrm{x}$

Mansfield, C. and T. Beths, 2015. Management of acute pancreatitis in dogs: A critical appraisal with focus on feeding and analgesia. J. Small Anim. Practice, 56: 27-39. DOI: 10.1111/jsap.12296

Mathews, K.A., 2000. Pain assessment and general approach to management. Vet. Clinics North Am.: Small Anim. Practice, 30: 729-752. DOI: $10.1016 / \mathrm{S} 0195-5616(08) 70004-4$

Mathews, K.A., 2008. Neuropathic pain in dogs and cats: if only they could tell us if they hurt. Vet. Clinics North America: Small Animal Practice, 38: 1365-1414. DOI: 10.1016/j.cvsm.2008.09.001

Mathews, K.A., P.V. Kronen, D. Lascelles, A. Nolan and S. Robertson et al., 2014. Guidelines for recognition, assessment and treatment of pain. J. Small Anim. Practice, 55: E10-E68. DOI: 10.1111 jsap. 12200

Melzack, R., 1999. From the gate to the neuromatrix. Pain, 82: S121-S126. DOI: 10.1016/S0304-3959(99)00145-1

Muir III, W.W., 2009. Physiology and Pathophysiology of Pain. In: Handbook of Veterinary Pain Management, Gaynor, J.S. and W.W. Muir III (Eds.), Mosby Elsevier, St. Louis, USA, ISBN-10: 0323062903, pp: 13-41.
Morgaz, J., R. Navarrete, P. Muñoz-Rascón, J.M. Domínguez and J.A. Fernández-Sarmiento et al., 2013. Postoperative analgesic effects of dexketoprofen, buprenorphine and tramadol in dogs undergoing ovariohysterectomy. Res. Vet. Sci., 95: 278-282. DOI: 10.1016/j.rvsc.2013.03.003

Orlandini, G., 2005. Elementi Di Fisiopatologia Del Dolore. In: La Semeiotica Del Dolore. I Presupposti Teorici E La Pratica Clinica, Orlandini, G. (Ed.), Antonio Delfino Editore, Roma, Italy, ISBN-10: 8872873185, pp: 31-133.

Parry, N.M.A., 2007. The canine prostate gland: Part 1 Non-inflammatory diseases. Companion Animal, 12: 37-40. DOI: 10.1111/j.2044-3862.2007.tb00128.x

Poole, J.W., R.J. Sammartano and S.J. Boley, 1987. Hemodynamic basis of the pain of chronic mesenteric ischemia. Am. J. Surgery, 153: 171-176. DOI: 10.1016/0002-9610(87)90809-9

Reid, J., A.M. Nolan, J.M. Hughes, D. Lascelles and P. Pawson et al., 2007. Development of the short- form Glasgow composite measure pain scale (CMPS-SF) and derivation of an analgesic intervention score. Animal Welfare 16, 97-104.

Simpson, K.W., 2007. Patologie dello stomaco. In: Clinica medica veterinaria. Malattie del cane e del gatto. Ettinger, S.J. and E.C. Feldman (Eds.), Elsevier Masson, Milano, Italy, ISBN-10: 8821429954, pp: 1339-1361.

Specht, A., D. Chan, T. O'Toole, M. Kent and J. Benson et al., 2002. Acute staphylococcal peritonitis following cystocentesis in a dog. J. Vet. Emergency Critical Care, 12: 183-187. DOI: 10.1046/j.1435-6935.2002.00037.x

Tsai, T.Y., S.K. Chang, P.Y. Chou, L.S. Yeh, 2013. Comparison of postoperative effects between lidocaine infusion, meloxicam and their combination in dogs undergoing ovariohysterectomy. Vet. Anaesthesia Analgesia, 40: 615-622.

DOI: $10.1111 /$ vaa. 12064

Webb, C. and D.C. Twedt, 2003. Canine gastritis. Vet. Clininics North America: Small Animal Practice, 33: 969-985. DOI: 10.1016/S0195-5616(03)00052-4

Weinstein, J., K. Beck, M. Quinn and C. Jessen, 2005. Evaluation of the abdomen using ultrasound following a ventral midline celiotomy. Vet. Radiology Ultrasound, 46: 337-339. DOI: $10.1111 / \mathrm{j} .1740-8261.2005 .00063 . \mathrm{x}$

Whittemore, J.C. and V.L. Campbell, 2005. Canine and feline pancreatitis. Compendium Continuing Education Practicing Veterinarian, 27: 766-776.

Wiese, A.G., 2015. Assessing Pain-Pain Behaviors. In: Handbook of Veterinary Pain Management. Gaynor, J.S. and W.W. Muir (Eds.), Mosby Elsevier, St. Louis (Missouri),

ISBN-10: 978-0-323-08935-7, pp: 67-97. 
Willard, M., 2006a. Malattie Dello Stomaco. In: Medicina Interna Del Cane e Del Gatto. Richard W. Nelson, C. Guillermo Couto (Eds.) Masson-Edizioni Veterinarie, Milano, Italy, pp: 428-440. ISBN-10: 8821432793

Willard, M., 2006b. Malattie Del Tratto Intestinale. In: Medicina Interna Del Cane E Del Gatto. Nelson, R.W. and C.G. Couto (Eds.) Masson-Edizioni Veterinarie, Milano, Italy, pp: 441-475. ISBN-10: 8821432793

Willard, M., 2006c. Malattie Del Peritoneo. In: Medicina Interna Del Cane E Del Gatto. Nelson, R.W. and C.G. Couto (Eds.) Masson-Edizioni Veterinarie, Milano, Italy, pp: 476-479. ISBN-10: 8821432793

Williams, D.A. and J.M. Steiner, 2007. Malattie Del Pancreas Esocrino Nel Cane. In: Clinica Medica Veterinaria, Malattie Del Cane e Del Gatto. Ettinger, S.J. and E.C. Feldman (Eds.), Elsevier Masson, Milano, Italy, pp: 1518-1524.

ISBN-10: 8821429954.
Wong, H.Y. and E.A. Mayer, 2006. A Clinical Perspective on Abdominal Pain. In: Wall and Melzack's Textbook of Pain, McMahon, S.B. and M. Koltzenburg (Eds.), Elsevier, New York, USA, ISBN-10: 0443067910, pp: 753-776.

Wooten, J.G., B.D. Lascelles, V.L. Cook, J.M. Law and A.T. Blikslager, 2010. Evaluation of the relationship between lesions in the gastroduodenal region and cyclooxygenase expression in clinically normal dogs. Am. J. Vet. Res., 71: 630-635. DOI: 10.2460/ajvr.71.6.630

Zimmermann, M., A.G. Raiser, A. Mazzanti, S.T. Dos Anjos Lopes and Z. Salbego, 2006. Peritonite em cães. Ciencia Rural, 36: 1655-1663.

DOI: $10.1590 / \mathrm{S} 0103-84782006000500052$ 